Susan Sontag, Reborn: Journals and Notebooks 1947-1963

(editado por David Rieff).

(Farrar, Straus \& Giroux, primera edición, diciembre de 2008, 336 páginas).

\title{
SUSAN SONTAG: \\ CULPAS LITERARIAS, CULPAS MORALES
}

\author{
Jorge Edwards
}

$\mathrm{M}$

e enteré hace poco de la existencia de un libro póstumo, hecho de páginas de diario y notas inéditas de adolescencia y juventud, de Susan Sontag, y entré en acción hasta conseguir un ejemplar. Calculo que gran parte de mi vida en Chile, adolescencia y juventud incluidas, precisamente, ha estado dedicada a este ejercicio, a la búsqueda de libros muy difíciles de encontrar en estos lados: el Saint Genet, de Jean-Paul Sartre, para citar un ejemplo entre muchos otros, o, en una época, los cuentos de Isak Dinesen o las novelas de Machado de Assis. La lista sería interminable y quizá divertida, a pesar de su lado provinciano. Me digo a veces que si los libros de este mundo estuvieran en las librerías de Santiago, a la vuelta de la esquina, la curiosidad, la intensidad de la lectura, la fascinación, la pasión intelectual, probablemente serían menores. Este libro, Reborn, con el subtítulo en inglés de Diarios y Libros de Apuntes, 1947-1963, fue editado en Nueva York por David Rieff, hijo de la escritora, autor, él mismo, de ensayos y reportajes políticos de notable calidad. El título fue sacado por su editor

Jorge Edwards. (1931). Escritor y ensayista chileno. Premio Nacional de Literatura (1999) y Premio Cervantes de Literatura (1999). Sus novelas más recientes son La Casa de Dostoievsky (Planeta, 2008), El Inútil de la Familia (Alfaguara, 2004) y El Sueño de la Historia (Tusquets, 2000). 
del texto mismo, de un momento de gran intensidad, porque todo el libro es de pasión, asombro, descubrimiento del mundo en todos sus aspectos, y sobre todo en su erotismo, en su belleza, en su arte y su pensamiento, en su misterio. En una nota de mayo de 1949, en vísperas de viajar desde California a la Universidad de Chicago (Susan Sontag había nacido en 1933), la autora adolescente escribió:

Conozco la verdad ahora - Sé lo bueno y justo que es amar Me han dado, en alguna parte, permiso para vivir Todo comienza desde ahora - He renacido

El prólogo de Rieff a la recopilación de anotaciones personales de su madre es fuera de serie, atrevido y conmovedor. Confiesa que decidió hacer él la edición antes de que la hiciera otro, y reconoce que hay cosas en estos diarios y libros de apuntes que son "una fuente de dolor” para él, y muchas que habría preferido no conocer y no dar a conocer a otros. Sin embargo, piensa el lector, no conocerlas habría significado no conocer de verdad, en todas sus debilidades y sus grandezas, a la autora, que llegó a ser, al final de su recorrido, uno de los grandes personajes y uno de los mitos intelectuales femeninos de la literatura del siglo XX. En otras palabras, las anotaciones de la joven Sontag no podían perderse, y en ese caso, era mejor que las diera a conocer él mismo, con fidelidad, con amor filial auténtico y con instantes inevitables de incomodidad.

Los primeros apuntes de Susan Sontag son de 1947, cuando ella sólo había cumplido los catorce años de edad. Por asombroso que parezca, la Sontag de esos días, con bastante ingenuidad, con un tono más o menos solemne, con una conciencia clara de su talento, de su originalidad como personaje, es, a pesar de todo, la misma de sus ensayos célebres de madurez, la de Contra la Interpretación o de La Enfermedad y sus Metáforas. En su primera entrada, de noviembre del 47, la escritora adolescente enumera su ideario esencial:

Yo creo, anota:

a) Que no hay un dios personal ni vida después de la muerte;

b) Que lo más deseable del mundo es la libertad para ser fiel consigo mismo, esto es, Honestidad;

c) Que la única diferencia entre seres humanos es la inteligencia... 
Y su ideario precoz continúa en la misma línea. Hacia fines del año siguiente, después de haber leído bastante bien a Franz Kafka, a Thomas Mann, a André Gide, se propone una lista de libros de lectura urgente: obras de William Faulkner, Sherwood Anderson, Ludwig Lewishon, George Moore, Dostoievsky, Joris Karl Huysmans, entre muchísimos otros. De paso, anuncia que leerá poemas de Dante, Ariosto, Tasso, Heine, Pushkin, Rimbaud, Verlaine, Apollinaire, y obras de teatro de Synge, O’Neill, Calderón, Shaw, Hellman... Su hijo y editor comenta que la lista continúa durante cinco páginas y abarca más de cien títulos. Habría sido interesante que la publicara completa. Habría sido, quizá, uno de los programas de lectura de adolescencia más extraordinarios de nuestro tiempo.

En 1949, en la Universidad de California, en Berkeley, entra en un ritmo desaforado de farra, de alcohol, de droga, de amores lesbianos, de trasnochadas en lugares peligrosos. Escribe: estoy enamorada de estar enamorada. Sufre de mala conciencia, se cree anormal, más anormal de lo que nos parece a nosotros, sus lectores después de más de medio siglo, y no abandona sus feroces atracones de literatura clásica, de música, de filosofía, de museos y exposiciones. Su vida es intensa, desbocada. A cada rato da la impresión de que no tiene tiempo de redactar frases normales, dotadas de sujeto y predicado. Sólo anota, enumera, exclama. "Dios, escribe esta no creyente de dieciséis años de edad: ¡vivir es enorme!” Renace con cada nueva experiencia, decide, sin alegría, con sentimientos de culpa, aceptar su homosexualidad, relativa, como se verá más tarde, y eso explica el título de la recopilación.

Susan Sontag comenzó a leer y escribir en los años de Sartre, de Heidegger, de Albert Camus, de William Faulkner, de Cesare Pavese, y en los finales de Thomas Mann y André Gide. Asistió a una primera y magnífica versión de Muerte de un Vendedor, de Arthur Miller, y después ordenó en su diario una lista de obras musicales. Encabeza la lista uno de los conciertos para piano y orquesta de Dimitri Shostakovich. S. S. deja después un espacio en blanco.

“¡Sexo con música, exclama, qué intelectual! (So intellectual!!!)”

Es una época que conocimos en Chile a nuestro modo, quizá con algo de gazmoñería, aunque no estoy tan seguro, pero con inusitada pasión y sin duda menos libros, menos medios, menos espectáculos. Susan Sontag, que proclama en diversas entradas su admiración 
por La Montaña Mágica y por Doctor Faustus, se consiguió un buen día el teléfono de Thomas Mann, que vivía en California. Organizó de inmediato un encuentro y partió a visitarlo con un par de amigos. "Hoy, escribe el 28 de diciembre de 1949, en compañía de E y de F, interrogamos a Dios... Su mujer, delgada, de cara y pelo gris, abrió la puerta. Él, al final del amplio living, sentado en un sofá, sostenía con un collar un gran perro negro que habíamos escuchado ladrar mientras nos acercábamos... Terno beige, corbata marrón, zapatos blancos, pies juntos, rodillas separadas... Su hablar es lento y preciso, y su acento es mucho menos prominente de lo que esperaba.”

¿Qué entendería Sontag por un acento prominente? ¿Por qué pensaba que un escritor tenía que hablar como un actor de teatro? En todo caso, a pesar de su insolencia juvenil, quedó impresionada. Y las cosas que le dijo Mann darían para un ensayo separado. Al maestro, por ejemplo, le costaba apreciar la belleza del lenguaje de James Joyce porque "no había nacido en la cultura inglesa". Pero lo admiraba, y pensaba que entre ambos había un rasgo en común: el uso del mito en sus obras. Creía que La Montaña Mágica era una novela de educación, “como todas las novelas alemanas”. En cuanto al Doctor Faustus, era un libro al modo de Nietzsche, escrito entre 1942 y 1946. Para escribirlo contó con la colaboración de un discípulo de Alban Berg, de apellido Darnoldi, pero también conversó muchas veces con Arnold Schoenberg en persona y estudió su Tratado de Armonía.

Cuando consignaba estas cosas en su diario de vida, Susan Sontag todavía no cumplía los 17 años de edad. ¡Qué tiempos, diríamos nosotros, qué mundos, qué niña casi prodigio! A medida que el diario avanza, la escritura se afirma, es más lúcida, menos ingenua, y, a la vez, más angustiada y dubitativa. Uno tiene una impresión constante de sensualidad, de insaciable curiosidad, de frustración, de dificultad de vivir. Sontag no es en absoluto una escritora amable, sonriente, fácil. Hay momentos de notoria e incluso injusta agresividad literaria. El tono provocativo de Contra la Interpretación ya se advierte con claridad, como si dominara el estilo, en las anotaciones de comienzos de la década de los sesenta, que preceden por muy poco a su gran colección de ensayos. Estas notas pueden leerse como una preparación y una introducción. Después de sus años universitarios en los Estados Unidos, tiene dos experiencias vitales formativas, que la llevan a la plena madurez: la de vivir en París durante algunos años y la de instalarse 
después en Nueva York. Alaba muchas veces, de diversas maneras, las formas de vida de la gran ciudad. Hasta la "fealdad" neoyorquina, su trepidación, su ritmo, su bullicio, le parecen atractivos en alguna forma. Tiene una permanente conciencia de que escribir es su única manera de vivir: lo único que en definitiva la redime. Tiende a ser autobiográfica al extremo y a convertir la lectura en experiencia, en autobiografía. De ahí el carácter reflexivo, narrativo, original, inconfundible, de sus comentarios de escritores. Leer es una experiencia y criticar lo leído es una forma de narrar esa experiencia.

Se podría sostener que Sontag conoce bien, lee en profundidad y ama la literatura francesa, pero creo que hay en todo esto una contradicción notoria. Lo digo de una manera muy general, quizá arbitraria. La lectura detenida de los ensayos de Susan Sontag, y mi actual lectura de Reborn me lo confirma, me lleva a pensar que las virtudes clásicas de la literatura francesa - equilibrio, racionalidad, algo que André Gide llamaba claridad profunda-, molestan e irritan a nuestra ensayista, a pesar de que no termina de reconocer su molestia. Menciona muchas veces a Montaigne, y quizá no puede hacer menos, pero siempre se refiere a él con frialdad, como al pasar, con escasa simpatía. Observa con acierto que Montaigne presenta en sus ensayos una autobiografía siempre cambiante, llena de sorpresas, y que consigue presentar su yo de este modo gracias a su enorme habilidad literaria. Por otro lado, Sontag sabe que pertenece a la numerosa familia de los escritores del yo, de la subjetividad, y sospecha que esa estirpe predomina en Francia desde Montaigne hasta hoy. Al final se inclina, sin embargo, del lado de los memorialistas excesivos, farragosos, provocadores. Habla con regocijo, con fruición, de la "monstruosidad" de Jean Genet, captada con genio y en forma desordenada por el Sartre de Saint Genet, Comédien et Martyr, y concluye que la reinvención de Genet por Jean-Paul Sartre, a pesar de sus excesos verbales, de sus lados oscuros, es mejor que muchos de los textos clásicos del autor de El Ser y la Nada. En cambio, su visión de Albert Camus es más bien peyorativa, burlona, agresiva. Afirma, por ejemplo, en su ensayo sobre los carnets de Camus recopilado en Contra la Interpretación, que es "el marido ideal de la literatura contemporánea", pero resulta claro, en la escritura de ella, que esa descripción se aplica a una relación fría, educada, cortés, burguesa. El mundo de Sontag no es de "maridos ideales" ni nada que se parezca: es de amantes, de amores torcidos, de 
insatisfacción esencial. La época obligó a Camus a escribir sobre dementes y desequilibrados, pero lo hizo, sostiene Sontag, con un aire de razonabilidad, mesura (la cursiva es de ella), fluidez, graciosa impersonalidad. En otras palabras, Camus salió de un nihilismo que flotaba en el aire, pero lo dejó atrás y se contradijo con él. Ella, en cambio, fue sartriana hasta las últimas consecuencias, sin dejar de comprender las limitaciones de Jean-Paul Sartre, y ama el estilo confesional impúdico, chocante, violento, de Genet en sus grandes poemas autobiográficos en prosa (Notre Dame des Fleurs, etcétera). En Reborn, hay páginas de autobiografía difícil, de provocación abierta (las que causaban la confesada incomodidad de su hijo David Rieff). El 23 de agosto de 1961, en Nueva York, escribe: "Pasé una hora esta tarde (mientras ella estaba abajo en el puerto) masturbándome y estudiando mi sexo con un espejo. Se lo conté cuando ella regresó. ¿Descubriste algo?, me preguntó. No, fue mi respuesta."

Mi impresión personal: trata de poner dinamita en el memorialismo francés tradicional, el de Montaigne, el de Jean-Jacques Rousseau, el de los escritos íntimos de Stendhal, y de llevarlo más lejos. Respeta los diarios de André Gide debido a su enorme cultura, su inteligencia y sus dones narrativas. Siempre hay una historia sorprendente, a menudo sugerida, contada a medias, en una página autobiográfica de Gide. En cambio, desdeña al "equilibrado, educado, refinado" Albert Camus. Y describe con notable sutileza al Michel Leiris de Age D'homme: un perfecto funcionario del Museo del Hombre, un etnólogo profesional, un personaje de estricta rutina, y sin embargo, a la vuelta de sus páginas autobiográficas, un perverso. Susan Sontag se complace en contarnos las debilidades secretas de Leiris, su miedo enfermizo de las mujeres, su impotencia, sus continuas infecciones en las partes más íntimas del cuerpo. Es una máscara, un autómata, un perverso dominado por sus perversiones y que las transforma en materiales literarios, $\mathrm{y}$ esto, para nuestra ensayista, lo salva como escritor.

Reborn es una gran lectura, un texto sin desperdicio, una escritura que salpica las páginas, que lanza chispas y que parece en muchos pasajes anterior a la sintaxis, a la frase armada, provista de sujeto, verbo y predicado. Es una sucesión de propósitos anotados y no cumplidos, de exclamaciones, de entusiasmos, de furibundas autocríticas. Por ejemplo, el 15 de septiembre de 1961: 
1.- No repetirme.

2.- No tratar de ser divertida.

3.- Sonreír menos, hablar menos...

La lista es larga y tiene un aspecto deliberadamente cómico. "Piensa en Blake, escribe más adelante. No sonreía para los otros.”

Sontag sabe que es una escritora del yo, que sus posibilidades narrativas se dan mejor en la narración autobiográfica o en la ficción apegada a la memoria y la historia personal. Respeta, por eso, el propósito de veracidad, de "sinceridad", de muchos escritores franceses. Pero sólo se entusiasma cuando descubre que el trabajo de la memoria personal conduce a sectores extraños, anormales, delirantes de la conciencia. De ahí su admiración incondicional por Genet y por el Sartre que explora los textos de Genet sin la menor medida literaria, extraviándose sin miedo en fárragos verbales y recuperando los hilos. Me parece que no conoció demasiado bien a los franceses desmesurados, a los seguidores de la prosa de Francois Rabelais, una línea en la que podrían figurar Honorato de Balzac en algunas de sus novelas y el ocultista y medievalista Victor Hugo, sobre todo el de Cosas Vistas, un diario de vida que no es demasiado ajeno a Reborn. En cambio, es notoria su afinidad con escritores del mundo germánico: Kleist, Kafka, Thomas Mann, Bertolt Brecht. Y, desde luego, Federico Nietzsche, cuya sola mención la empuja a entrar en uno de sus trances exclamativos ("Nietzsche! Nietzsche! Nietzsche!"). En uno de los párrafos finales de su diario, escrito el 15 de septiembre de 1962 a la 1.30 de la madrugada, resume su visión de la literatura y de ella misma en la literatura:

Uno es un escritor del exterior (Homero, Tolstoy) o del interior (Kafka). El mundo o la locura. Homero y Tolstoy, como la pintura figurativa, tratan de representar el mundo con sublime claridad, más allá de todo juicio. O bien, destapar nuestra locura. El primero es mucho más grande. Sólo podré ser un escritor de la segunda especie.

En otras palabras, sólo puede aspirar a sacar a flote su locura, sus demonios subjetivos. No sé si consigo seguirla hasta aquí. Su síntesis me parece un tanto arbitraria. Franz Kafka construyó un mundo autónomo, autosuficiente, a partir de sus demonios personales. No se propuso representar el mundo real, y menos a la manera de la pintura figurativa, pero elaboró universos verbales que valen como 
grandes metáforas de la realidad y que actúan como representaciones opacas, como espejos deformantes, como símbolos que no admiten una interpretación determinada, que carecen de toda equivalencia. Entramos aquí, precisamente, al espacio de los grandes ensayos que siguieron a estos apuntes, los reunidos en Contra la Interpretación. Susan Sontag no sólo fue una escritora del yo, del interior, como lo demuestra a cada rato en las páginas de Reborn. Fue también una crítica formidable, que hizo de la crítica un gran arte literario, como algunos otros escritores del siglo XX, como Roland Barthes, como Edmund Wilson, como el Thomas Mann de los ensayos sobre Tolstoy y Goethe o sobre el Quijote. Tenía, eso sí, una tendencia curiosa a autocastigarse, un sentimiento de culpa moral y literaria que introduce una sombra constante en su escritura. Y que le confiere, precisamente, un carácter propio, un sello inconfundible. $\square$

Palabras clave: Susan Sontag; biografía de Susan Sontag; apuntes de adolescencia y juventud de Susan Sontag. 